\title{
Influence of morphine on TLR4/ NF-kB signaling pathway of MCF-7 cells
}

\author{
Haghjooy-Javanmard $\mathrm{S}^{1}$, Ghasemi A ${ }^{1}$, Laher $\mathrm{I}^{2}$, Zarrin $\mathrm{B}^{1}$, Dana $\mathrm{N}^{1}$, Vaseghi $\mathrm{G}^{3}$ \\ Isfahan Cardiovascular Research Center, Cardiovascular Research Institute, Isfahan University of Medical Sciences, \\ Isfahan, Iran.golnazvaseghi@yahoo.com
}

\begin{abstract}
Morphine affects the risk of metastasis in cancer. The TLR4 gene promotes migration in adenocarcinoma cells. We investigated the effect of morphine on TLR4, MyD88 and NF-K B-expression and migration. Migration of estrogen receptor-positive MCF7 breast cancer cells was studied after 24 and 48 hours incubation with morphine, with boyden chamber method. Morphine effect on TLR4, MyD88 and NF-KB mRNA expression was determined by quantitative Real-Time polymerase chain reaction. Migration was reduced at the doses of 0.5 and $5 \mu \mathrm{M}(\mathrm{p}<0.05)$. However, TLR4, MyD88 and NF-KBmRNA expression was decreased at the doses of $0.5,5$ and $500 \mu \mathrm{M}$. Morphine at the dose of $50 \mu \mathrm{M}$ increased the expression of mentioned genes. MCF-7 cell line after 48 hours incubation with the dose of $0.5 \mu \mathrm{M}$ morphine decreased the migration and at the dose of $0.5 \mu \mathrm{M}$ down-regulated the mRNA expression of TLR4, MyD88 and NF-KB, however, the higher doses increased the expression of TLR4, MyD88 and NF-KB. Morphine affects TLR4expression in breast cancer cell, which depends on time and concentration (Tab. 1, Fig. 5, Ref. 24).

KEY WORDS: MCF7, breast cancer, TLR4, MyD88, NF-kB, morphine.
\end{abstract}

List of abbreviations: DMEM - Dulbecco's Modified Eagle's medium, ELISA - enzyme-linked immunosorbent assay, FBS fetal bovine serum, IL-1 $\beta$ - interleukin 1 beta, LPS - Lipopolysaccharide, MMP - matrix metalloproteinases, MyD88 - myeloid differentiation primary-response gene 88 , NF- $\mathrm{BB}$ - Nuclear factor kappa-light-chain-enhancer of activated B cells, QRT-PCR - Quantitative real-time reverse transcriptase-polymerase chain reaction, TLR4 - Toll-like receptor-4, VEGF - vascular endothelial growth factor.

\section{Introduction}

Breast cancer is the most common malignancy in women and the second leading cause of cancer deaths, which is often related to recurrence and metastasis (1). Although the primary treatment is with surgical resection of the localized tumor, tumor cells may spread into the lymphatic and blood stream after surgery. Opioids,

${ }^{1}$ Isfahan Cardiovascular Research Center, Cardiovascular Research Institute, Isfahan University of Medical Sciences, Isfahan, Iran, ${ }^{2}$ Department of Anesthesiology, Pharmacology and Therapeutics, University of British Columbia, Vancouver, BC, Canada, and ${ }^{3}$ Isfahan Cardiovascular Research Center, Cardiovascular Research Institute, Isfahan University of Medical sciences, Isfahan, Iran

Address for correspondence: G. Vaseghi, Applied Physiology Research Center, Isfahan University of Medical Sciences, Hezar-Jarib Avenue, 81676-36954, Isfahan, Iran.

Phone: +98.313 .6692836$

Acknowledgments: These data were from a MSc thesis supported by the Isfahan University of Medical Sciences, No. 394932. which are used to control surgical pain in end-stage cancer patients, can also suppress immune function and promote angiogenesis. Morphine is one of the most effective analgesics administrated to cancer patients. The effect of morphine on tumor growth, metastasis and angiogenesis is inconclusive in animals (2), although in-vitro studies suggests that morphine influences proliferation, survival, migration, adhesion and invasion of multiple cancer cell types (3).

Some studies report that morphine promotes and increases cancer proliferation and metastasis, while others demonstrate a prevention of cancer progression (4). Differences in dosage, study design and even the existence unique genes in cancer cell lines may underlie these conflicting results. A single dose of morphine is able to influence the expression of some genes, although the role of opioid receptors in this process is unknown (5).

Morphine activates the innate immune receptor Toll-like receptor 4 (TLR4), increases the production of pro inflammatory cytokines via myeloid differentiation factor 88 (MyD88), and nuclear factor kappa B (NF- $\mathrm{kB})$ dependent on the intracellular pathway $(6,7)$. Morphine also increases TLR4 expression $(6,7)$. The interaction of morphine with TLR4, which occurs in a nonstereoselective manner $(8,9)$, is thought to mediate neuroinflammatory responses to opioids by reducing the analgesic action of opioids and so to contribute to opioid tolerance.

Human breast cancer expression and activation of TLR4 correlates with shorter survival times (10). Studies in several cancer models show that activation of tumor-expressed TLR4 promotes the expression of angiogenic and inflammatory factors, and increases invasiveness and metastatic spread (11). After TLR4 stimulation, breast cancer cells produce matrix metalloproteinases- 2 
(MMP-2) and 9 (MMP-9) and also vascular endothelial growth factor (VEGF). The expression of TLR4 increases tumor volume, while also promoting metastatic lesions in the liver in a breast cancer model $(12,13)$.

We used MCF-7 cells (an estrogen positive human breast cancer cell line) to examine the hypothesis that morphine interacts with the TLR4, MyD88 and NF- $\kappa$ B signal transduction pathway to regulate breast cancer cell migration by increasing the secretion of IL-1 $\beta$ as a downstream proinflammatory effector molecule.

\section{Materials and methods}

\section{Cell cultures}

Estrogen receptor-positive human breast adenocarcinoma cells (MCF7) were obtained from Pasteur Institute (Tehran, Iran); MCF7 cells are estrogen receptor-positive human breast adenocarcinoma cell line. Cells were cultured in DMEM 15 medium supplemented with $10 \%$ fetal bovine serum (FBS), $2 \mathrm{mM} \mathrm{L}$-glutamine, and $1 \%$ penicillin-streptomycin. The cells were incubated at $37{ }^{\circ} \mathrm{C}$ in humidified air with $5 \% \mathrm{CO}_{2}$ and grown as monolayers in standard tissue culture dishes. The medium was changed every 3 days and passaged weekly. Cells were harvested when $70 \%$ confluent in culture.

\section{Drug exposure}

Cells were treated 24 and 48 hours with morphine $(0,0.005$, $0.05,0.5,5 \mu \mathrm{M})$; these concentrations are similar to those obtained clinically during intravenous administration $(5,14)$. The cells were then used for evaluating migration and gene expression, while their supernatants were used for detecting IL-1 $\beta$.

\section{Cell migration assay}

An in vitro migration assay was performed using uncoated membranes in transwell inserts ( 8 - $\mu \mathrm{m}$ pore size) (SPL, Life Sciences, Korea). Untreated (control) or morphine treated MCF7 cells $\left(3 \times 10^{4}\right.$ in $200 \mu \mathrm{l}$ serum-free medium) were seeded in the upper chamber, while the lower chamber contained $500 \mu \mathrm{l}$ of media with $20 \%$ FBS served as a chemoattractant. Non-migratory cells were removed from the top membrane after 12 hours of incubation in the chamber, while the cells that migrated were fixed and stained with a $0.05 \%(\mathrm{w} / \mathrm{v})$ crystal violet solution and counted using Matlab (15). Experiments were performed three times in triplicate.

\section{RNA extraction and polymerase chain reaction}

Total RNA $(2 \mu \mathrm{g})$ was treated with DNA-se I and reverse transcribed using random hexamers and SuperScript II reverse

Tab. 1. Sequences of primers used in real time PCR.

\begin{tabular}{ll}
\hline Gene & qPCR primer sequence \\
\hline \multirow{2}{*}{ TLR4 (TOLL LIKE) } & F: 5':GAGGATGATGCCAGGATGATGTC 3' \\
& R: 5':GCCAAGTCTCCACGCAGG 3' \\
\hline \multirow{2}{*}{ NF-K $\beta$} & F: 5':ACATCGTGGTCGGCTTCG 3' \\
\hline \multirow{2}{*}{ MyD88 } & R: 5':TGTCATTCGTGCTTCCAGTG 3' \\
\hline
\end{tabular}

transcriptase (Invitrogen Ltd, UK). Primers were designed using Primer3 software (http://frodo.wi.mit.edu/cgi-bin/primer3/ primer3_www.cgi) and synthesized by Sigma-Aldrich (Ireland). The sequences of primers used for polymerase chain reaction (PCR) are available in Table 1. The PCR reaction was carried out in a $50 \mathrm{ml}$ mixture of $0.5 \mathrm{ml}$ of Taq polymerase (Invitrogen) and $1 \mathrm{ml}$ of cDNA and PCR products were then run on $2 \%$ agarose gel with a parallel $100 \mathrm{bp}$ DNA ladder (Promega, UK). Real-time PCR was carried out according to the manufacturer's instructions using the LightCycler RNA SYBR Green 1 Amplification Kit (Roche Applied Science). All the measurements were independently repeated six times $(n=6)$. The maximum concentration of total RNA template used was $0.5 \mu \mathrm{g} \mathrm{ml}^{-1}$. Data are presented as cycle thresholds $\left(C_{\mathrm{t}}\right)$, and a quantitative analysis was performed using the ${ }^{\Delta \Delta} C_{\mathrm{t}}$ method using the LightCycler version 4.0 software. Glyceraldehyde-3-phosphate dehydrogenase (GAPDH) expression levels were used to normalize the data.

\section{Cytokines enzyme-linked immunosorbent assay}

Quantitative determination of IL- $1 \beta$ concentrations in plasma were performed using a human instant enzyme-linked immunosorbent assay (ELISA) kit (eBioscience, San Diego, CA, USA) according to the manufacturer's instructions. Optical density was read using a VICTORX4 multilabel plate reader (PerkinElmer Life Sciences, Waltham, MA, USA) at $450 \mathrm{~nm}$. The concentrations of IL-1 $\beta$ were calculated from standard curves. All tests were performed in triplicate.

\section{Statistical analysis}

Data are reported as the mean \pm standard error of the mean (SEM) and followed a normal distribution of independent experiments. At least three independent experiments were made each time. Statistical analysis was performed using a one sample t-test and one-way ANOVA test. p-values less than 0.05 were considered significant.

\section{Results}

\section{Effect of morphine on migration}

Incubation with morphine $(0.5$ and $5 \mu \mathrm{M})$ for 24 hours decreased migration in breast cancer MCF7 cells (control: $8.0 \pm 1.0$ $\%$; $0.5 \mu \mathrm{M}: 3.5 \pm 0.5 \% ; 5.0 \mu \mathrm{M}: 3.2 \pm 0.25 \%$ ). After 48 hours of treatment with similar doses of morphine, migration values were not further affected (control: $8.5 \pm 0.8 \% ; 0.5 \mu \mathrm{M}$ : $2.6 \pm 0.9 \%$; $5.0 \mu \mathrm{M}: 8.5 \pm 2.5 \%$ ) (Fig. $1 \mathrm{~A}$ and $\mathrm{B}$ ).

\section{Effect of morphine on TLR4 mRNA expression}

Treatment of breast cancer cells with morphine altered the expression of TLR 4 genes. Morphine $(0.005 \mu \mathrm{M})$ decreased gene expression, while higher concentrations increased the expression of TLR 4 genes (Fig. 2A and B).

\section{Effect of morphine on MyD $88 m R N A$ and $N F-\kappa B m R N A$ expression}

Treatment of breast cancer cells with morphine $(0.005,0.05$, 0.5 and $5 \mu \mathrm{M}$ ) for 24 hours increased the expression of MyD- 88 
(A)

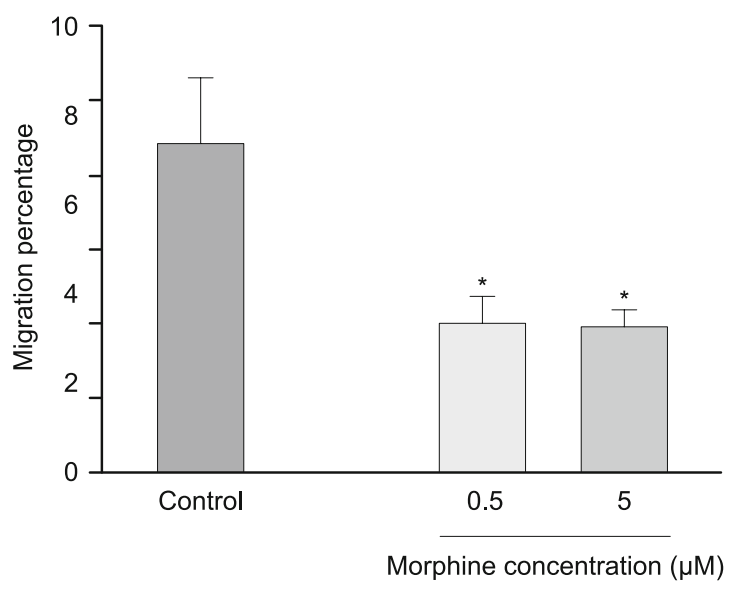

(B)

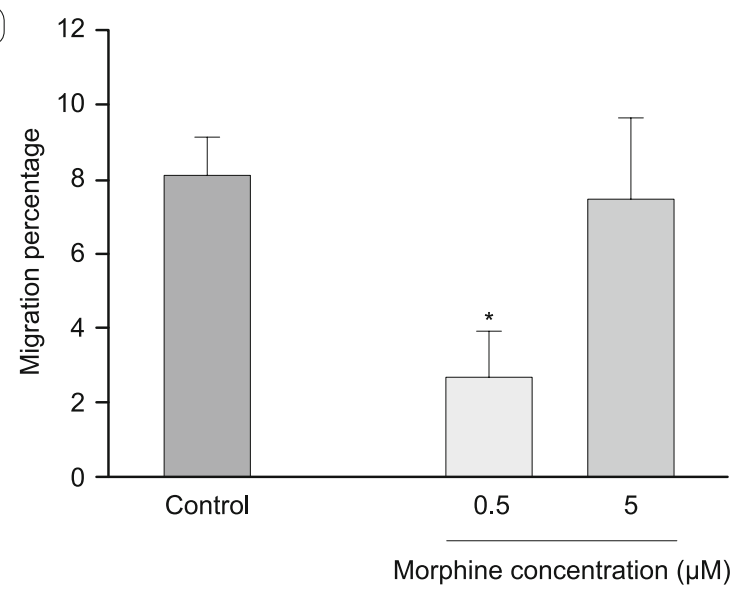

Fig. 1.A. Migration of the breast cancer cells after and 24 hours incubation with morphine or DMSO (control). Mean values $(n=3)$ are shown. $* p<0.05$ compared with control. B. Migration of the breast cancer cells after and 48 hours incubation with morphine or DMSO (control). Mean values $(n=3)$ are shown. * $p<0.05$ compared with control.

A

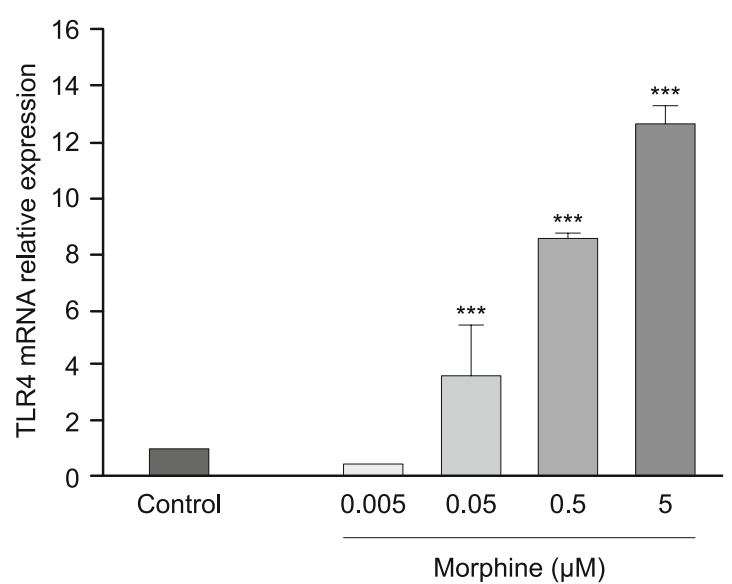

B

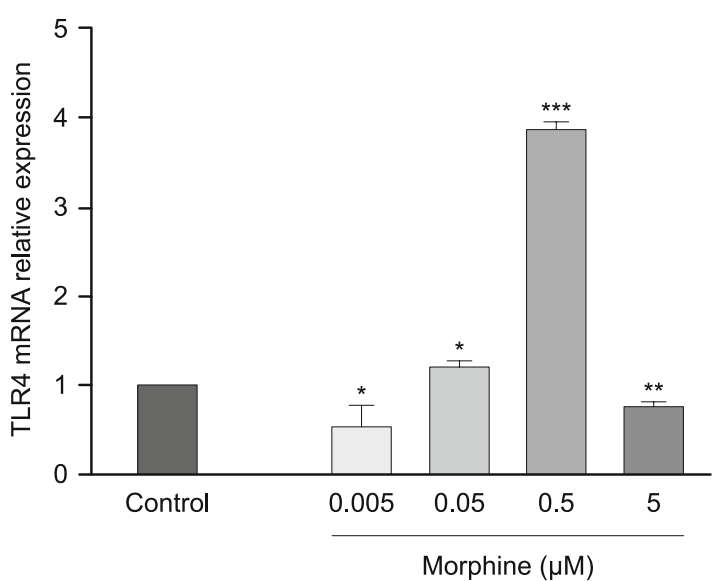

Fig. 2.A. Fold changes of TLR4 expression after incubation with various concentrations of morphine for $24-h o u r . * p<0.05$ and *** $p<0.001$ compared with the control. B. Fold changes of TLR4 expression after incubation with various concentrations of morphine for 48 hours. * $p<$ 0.05 and $* * * p<0.001$ compared with the control.

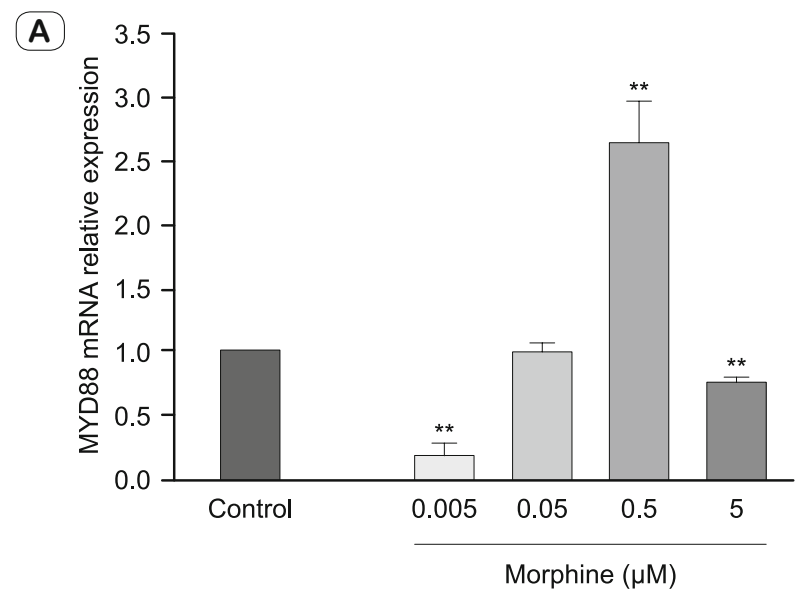

(B)

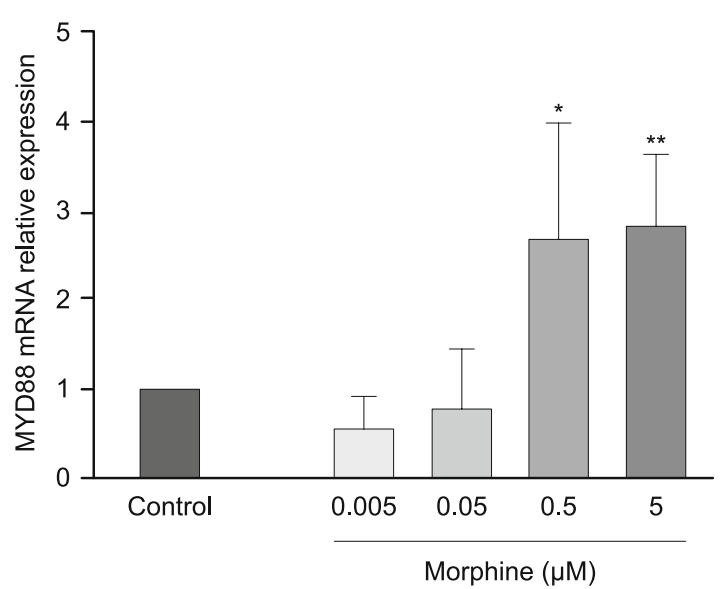

Fig. 3.A. Fold changes of MyD 88 expression after incubation with various concentrations of morphine for 24 hours. ** p $<0.01$ compared with the control. B. Fold changes of MyD 88 expression after incubation with various concentrations of morphine for 48 hours. * $p<0.05, * *$ p $<0.01$ compared with the control. 

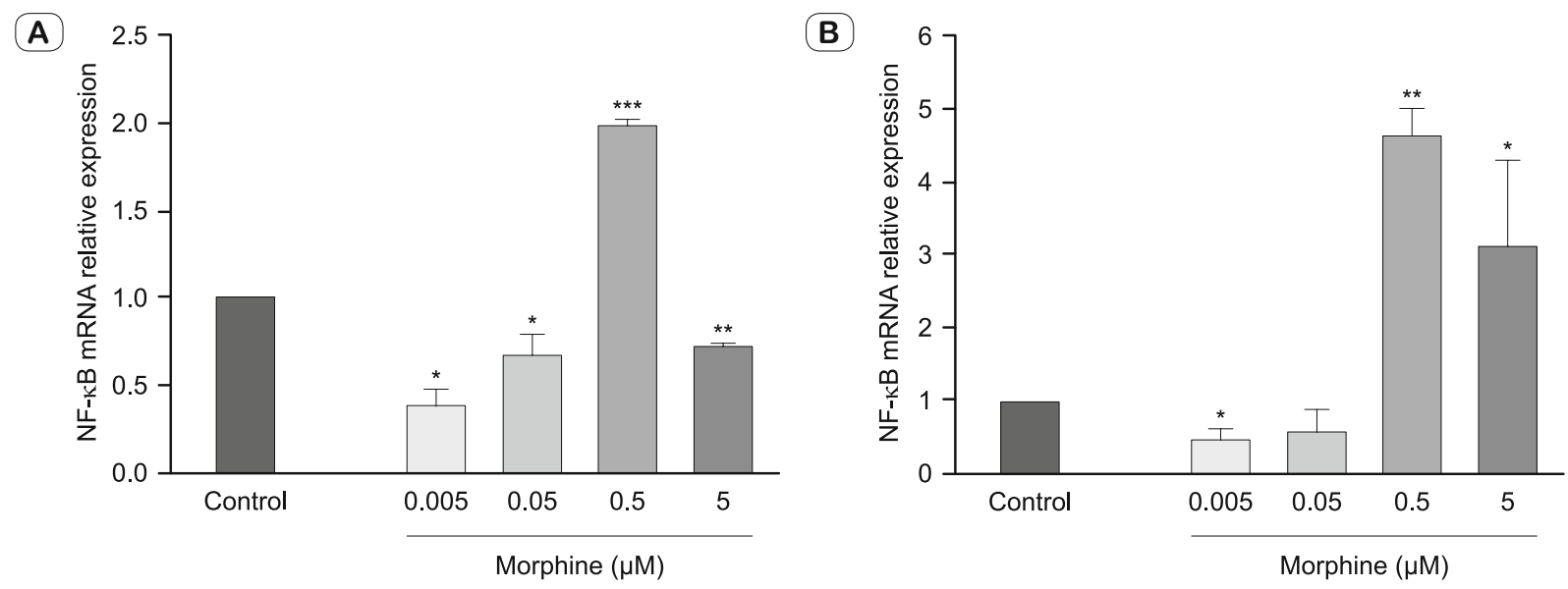

Fig. 4.A. Fold changes of NF-KB TLR4 expression after incubation with various concentrations of morphine for 24 hours. * $p<0.05$ and $* * p$ $<0.01$ compared with the control. B. Fold changes of NF-KB TLR4 expression after incubation with various concentrations of morphine for 48 hours. $* p<0.05$ and $* * p<0.01$ compared with the control.
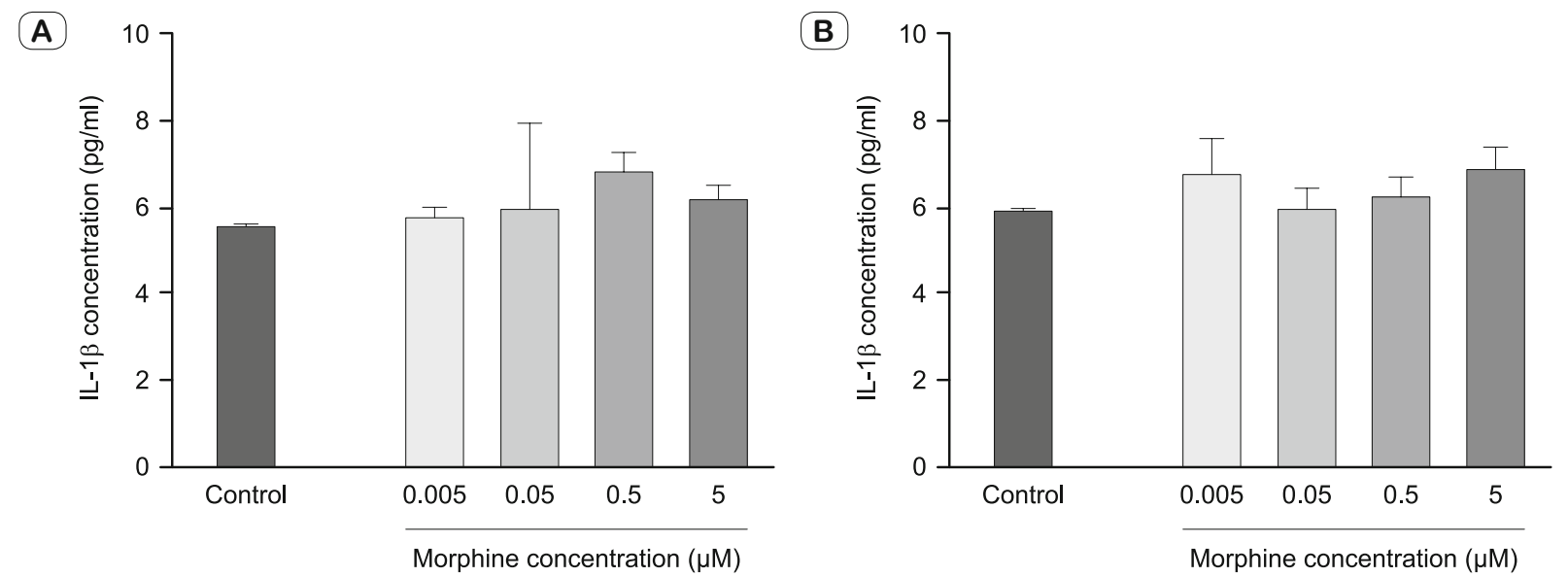

Fig. 5.A. Interleukin $1 \beta$ concentration after $24 \mathrm{~h}$ incubation of cells with morphine. B. Interleukin $1 \beta$ concentration after $48 \mathrm{~h}$ incubation of cells with morphine.

mRNA (Fig. $3 \mathrm{~A}$ and B). Morphine $(0.005,0.05,0.5$ and $5 \mu$. Decreased NF- $\kappa \mathrm{B}$ mRNA expression, but $0.5 \mu \mathrm{M}$ had the opposite effect after $24 \mathrm{~h}$ treatment. After $48 \mathrm{~h}$ morphine treatment at the doses of 0.50 and $5 \mu \mathrm{M}$, increased mRNA expression, however other doses decreased its expression (Fig. 4A and B).

\section{Effect of morphine on IL1 beta concentration}

There were no significant changes in IL- $1 \beta$ concentrations in the cells treated with morphine (Fig. 5A and B).

\section{Discussion}

This is the first study to our knowledge that investigates the direct effects of morphine on TLR4/MyD-88 in estrogen positive breast adenocarcinoma cell lines. Morphine is used to relieve pain in patients with terminal cancer and also after cancer surgery (16). Morphine relieves pain by acting directly in the central nervous system, and although its activity on peripheral tissue leads to many secondary complications, morphine is still considered the most effective drug clinically available for the management of severe pain associated with cancer (17). The effects of morphine on cell cancer growth were described either as inhibitory (18) or stimulatory (20) in the human cancer cell lines or in the animal in vivo models (19). One reason for these discrepancies could be the differences in morphine concentrations used, since we observed that lower concentrations of morphine decreased TLR 4 expression, while higher concentrations promoted the expression of TLR4. We also demonstrated that morphine produced biphasic effects on the cancer cell migration and TLR 4 mRNA expression, but with no clear dose-response relationships (20).

The activation of TLR4 expression in the tumor cells promotes tumor growth and resistance to apoptosis (21). Blockage of TLR4 signaling delays tumor growth and prolongs the survival of the animals (22). TLR4 and MyD88 expression in MCF-7 human breast cancer cells is increased by LPS stimulation (12), while knockdown of TLR4 inhibits proliferation and survival of breast 
cancer cells (22). We believe that the expression of this receptor by morphine as we observed in this study may contribute to metastasis in cancer patients.

The effect of morphine on the expression of TLR-4 was time dependent as we observed that exposure to high concentrations of morphine $(5 \mu \mathrm{M})$ for 48 hours decreased TLR 4 expression; this concentration of morphine is similar to that achieved in the plasma of the cancer patients receiving chronic morphine treatment for pain relief (14). Treating cells with lower concentrations of morphine $0.005 \mu \mathrm{M}$ for 24 hours mimicked the effects of a single morphine injection in the patients (23). The time-dependent effects of morphine on gene expression were previously reported (24).

We reported that morphine affected $N F-\kappa B$ gene expression in the breast adenocarcinoma cell and thus changed the cells' ability to migrate. Minimal changes were seen in IL $\beta$ concentrations in the cell supernatants, possibly due to the low concentration of this cytokine in MCF-7 cells.

In conclusion, we reported that morphine affected the expression of TLR-4-MyD 88 genes, which resulted in an increased migration of the estrogen positive human breast cancer cell line. Further studies are needed to evaluate the direct effects of morphine on the cell migration, and determining the protein end-products of the TLR-4 gene. Our data suggested that morphine should be used with caution in tumors expressing TLR 4, as there could be stimulation of migration.

\section{References}

1. Jemal A, Siegel R, Ward E, Murray T, Xu J, Thun MJ. Cancer statistics, 2007. Cancer J Clin 2007; 57 (1): 43-66.

2. Afsharimani B, Cabot P, Parat M-O. Morphine and tumor growth and metastasis. Cancer Metast Rev 2011; 30 (2): 225-238.

3. Gach K, Wyrębska A, Fichna J, Janecka A. The role of morphine in regulation of cancer cell growth. Naunyn-Schmiedeberg's Arch Pharmacol 2011; 384 (3): 221-230.

4. Zagon IS, Rahn KA, McLaughlin PJ. Opioids and migration, chemotaxis, invasion, and adhesion of human cancer cells. Neuropeptides 2007; 41 (6): 441-452.

5. Wandel C, Kim R, Wood M, Wood A. Interaction of morphine, fentanyl, sufentanil, alfentanil, and loperamide with the efflux drug transporter P-glycoprotein. J Amer Soc Anesthesiol 2002; 96 (4): 913-920.

6. Wang X, Loram LC, Ramos K, de Jesus AJ, Thomas J, Cheng K et al. Morphine activates neuroinflammation in a manner parallel to endotoxin. Proc Nat Acad Sci 2012; 109 (16): 6325-6330.

7. Franchi S, Moretti S, Castelli M, Lattuada D, Scavullo C, Panerai AE et al. Mu opioid receptor activation modulates Toll like receptor 4 in murine macrophages. Brain Behav Immun 2012; 26 (3): 480-488.hela

8. Hutchinson MR, Zhang Y, Shridhar M, Evans JH, Buchanan MM, Zhao TX et al. Evidence that opioids may have toll-like receptor 4 and MD-2 effects. Brain Behav Immun 2010; 24 (1): 83-95.
9. Hutchinson MR, Shavit Y, Grace PM, Rice KC, Maier SF, Watkins LR. Exploring the neuroimmunopharmacology of opioids: an integrative review of mechanisms of central immune signaling and their implications for opioid analgesia. Pharmacol Rev 2011; 63 (3): 772-810.

10. González-Reyes S, Marín L, González L, González LO, del Casar JM, Lamelas ML et al. Study of TLR3, TLR4 and TLR9 in breast carcinomas and their association with metastasis. BMC Cancer 2010; 10 (1): 1.

11. Hsu RY, Chan CH, Spicer JD, Rousseau MC, Giannias B, Rousseau $\mathrm{S}$ et al. LPS-induced TLR4 signaling in human colorectal cancer cells increases $\beta 1$ integrin-mediated cell adhesion and liver metastasis. Cancer Res 2011; 71 (5): 1989-1998.

12. Yang H, Wang B, Wang T, Xu L, He C, Wen H et al. Toll-like receptor 4 prompts human breast cancer cells invasiveness via lipopolysaccharide stimulation and is overexpressed in patients with lymph node metastasis. PloS One 2014; 9 (10): e109980.

13. Kim SH, Cho NH, Kim K, Lee JS, Koo BS, Kim JH et al. Correlations of oral tongue cancer invasion with matrix metalloproteinases (MMPs) and vascular endothelial growth factor (VEGF) expression. J Surg Oncol 2006; 93 (4): 330-337.

14. Zhao M, Zhou G, Zhang Y, Chen T, Sun X, Stuart C et al. betaarrestin2 inhibits opioid-induced breast cancer cell death through Akt and caspase-8 pathways. Neoplasma 2008; 56 (2): 108-113.

15. Castelli M, Panerai A, Sacerdote P, Franchi S. Measurement of Macrophage Toll-Like Receptor 4 Expression After Morphine Treatment. Opioid Recept Meth Protocols 2015: 263-271.

16. Lickiss JN. Approaching cancer pain relief. Eur J Pain 2001; 5: 5-14.

17. Mantyh PW. Cancer pain and its impact on diagnosis, survival and quality of life. Nature Reviews Neuroscience. 2006; 7 (10): 797-809.

18. Sueoka N, Sueoka E, Okabe S, Fujiki H. Anti-cancer effects of morphine through inhibition of tumour necrosis factor- $\alpha$ release and mRNA expression. Carcinogenesis. 1996; 17 (11): 2337-2341.

19. Sergeeva M, Grishina Z, Varfolomeyev S. Morphine effect on proliferation of normal and tumor cells of immune origin. Immunology letters. 1993 ; 36 (2): 215-218.

20. Ecimovic P, Murray D, Doran P, McDonald J, Lambert D, Buggy D. Direct effect of morphine on breast cancer cell function in vitro: role of the NET1 gene. British journal of anaesthesia. 2011; 107 (6): 916-923.

21. Kelly MG, Alvero AB, Chen R, Silasi D-A, Abrahams VM, Chan S, et al. TLR-4 signaling promotes tumor growth and paclitaxel chemoresistance in ovarian cancer. Cancer research. 2006; 66 (7): 3859-3868.

22. Yang H, Zhou H, Feng P, Zhou X, Wen H, Xie X, et al. Reduced expression of Toll-like receptor 4 inhibits human breast cancer cells proliferation and inflammatory cytokines secretion. Journal of Experimental \& Clinical Cancer Research. 2010; 29 (1): 1.

23. Tegeder I, Grösch S, Schmidtko A, Häussler A, Schmidt H, Niederberger E, et al. G Protein-independent G1 Cell Cycle Block and Apoptosis with Morphine in Adenocarcinoma Cells Involvement of p53 Phosphorylation. Cancer Research. 2003; 63 (8): 1846-1852.

24. Gach K, Szemraj J, Wyrębska A, Janecka A. The influence of opioids on matrix metalloproteinase-2 and-9 secretion and mRNA levels in MCF-7 breast cancer cell line. Molecular biology reports. 2011; 38 (2): 1231-1236. 